\title{
Programa de Erradicação do Trabalho Infantil: Concepções de Educandos e Famílias
}

\author{
Maria de Fatima Pereira Alberto \\ Universidade Federal da Paraíba, PB, Brasil. \\ Rafaela Rocha da Costa \\ Universidade Federal da Paraíba, PB, Brasil.
}

\author{
Manuella Castelo Branco Pessoa \\ Universidade Federal da Paraíba PB, Brasil. \\ Kassia Kiss Grangeiro Belém \\ Universidade Federal da Paraíba, PB, Brasil.
}

Suzany Ludimila Gadelha e Silva

Universidade Federal do Rio Grande do Norte, RN, Brasil.

\begin{abstract}
Resumo: O presente artigo analisa as contribuições do Programa de Erradicação do Trabalho Infantil (PETI) na perspectiva dos seus participantes: educandos e seus familiares. Participaram da pesquisa como educandos 359 crianças e adolescentes e 153 familiares. Utilizou-se uma entrevista semiestruturada, cujas questões versavam sobre o significado do PETI, os motivos de inserção dos educandos, os aspectos positivos e negativos acerca do programa e o que mudou em suas vidas após a entrada no programa. Para análise dos dados, utilizou-se a Análise de Conteúdo Temática e o SPSS. Os resultados mostram que a contribuição do PETI se dá prioritariamente na retirada de crianças e adolescentes de situações de risco, com menor ênfase no combate ao trabalho infantil. As atividades oferecidas estão mais no nível assistencial do que em processos educativos, limitando-se a brincadeiras, lazer e indicando a falta de um projeto pedagógico no programa. Constata-se também falta de capacitação dos educadores, o que faz com que o trabalho realizado por eles seja executado, muitas vezes, a partir do senso comum. Palavras-chave: Trabalho infantil, Políticas públicas, Crianças e adolescentes.
\end{abstract}

\section{PETI (Child Labor Eradication Program): students' and families' conceptions}

\begin{abstract}
This paper analyzes the contributions of the Government's Child Labor Eradication Program (PETI) in its participants' perspective: students and their families. 359 children and adolescents, and 153 families participated. A semi-structured interview including questions related to the meaning of PETI, to the reasons for students' inclusion, to the pros and cons regarding the program, and to the changes in students' lives after joining the program was conducted. Thematic content analysis and SPSS were used for data analysis. Results show that the contribution of PETI occurs predominantly in removing children and adolescents from risk situations, with less emphasis on combating child labor. The activities offered are more focused on the level of assistance than on the educational one, being restricted to plays and leisure, indicating the absence of a suitable pedagogical project. It is also noticeable a lack of qualified educators, what makes their work often based on common sense.
\end{abstract}

KeYworDs: Child labor, Public policy, Children and adolescents.

Pesquisa financiada pelo Conselho Nacional de Desenvolvimento Científico e Tecnológico (CNPq - Proc. $\left.\mathrm{n}^{\circ} 480.993 / 2009-2\right)$ 


\title{
PETI (Programa de Erradicación del Trabajo Infantil): concepciones de estudiantes y familias
}

\begin{abstract}
Resumen: En este trabajo se analiza la contribución del Programa para la Erradicación del Trabajo Infantil (PETI) en la perspectiva de sus participantes: los educandos y sus familias. Los participantes fueron 359 niños y adolescentes y 153 familiares. Se utilizó una entrevista semiestructurada cuyas cuestiones tratan sobre el significado del PETI, las razones de la inserción de los educandos, los aspectos positivos y negativos sobre el programa y lo que ha cambiado en sus vidas después de entrar en el programa. Para el análisis de los datos, se utilizó el análisis de contenido temático y el SPSS. Los resultados muestran que la contribución del PETI se presenta principalmente en la retirada de los niños y adolescentes en situación de riesgo, con menos énfasis en la lucha contra el trabajo infantil. Las actividades que se ofrecen están más en el nivel de la asistencia que en los procesos educativos, pues se limitan a reproducir los juegos y el ocio, lo que indica la ausencia de un proyecto pedagógico adecuado. También se constató la falta de educadores calificados, lo que hace con que el trabajo realizado por ellos sea hecho a menudo a partir del sentido común.

Palabras clave: Trabajo infantil, Políticas públicas, Niños y adolescentes.
\end{abstract}

\section{Introdução}

O presente artigo versa sobre as contribuições do Programa de Erradicação do Trabalho Infantil (PETI) na perspectiva dos participantes: os educandos (crianças e adolescentes) e seus familiares. Para isso, foram identificados o significado do PETI para esses atores, os motivos de inserção dos educandos, os aspectos positivos e negativos acerca do programa e o que mudou na vida dos educandos e de suas famílias após a entrada no programa.

Historicamente, o trabalho infantil existe desde a Antiguidade. Nesse período, assim como na Idade Média, o intento era o aprendizado de um ofício e a formação profissional. A preparação era feita quer no seio do ambiente doméstico, pelos próprios pais, quer nas corporações de ofício, pelos artífices e artesãos. A Revolução Industrial descaracterizou essa formação profissional e introduziu a exploração e o assalariamento, preconizou a criança e a adultizou, transformando as relações familiares (Nascimento, 1995). Na contemporaneidade, os fatores responsáveis pela existência do trabalho infantil decorrem de uma complexidade de elementos de ordem social, econômica, ideológica e subjetiva (Campos, \& Alverga, 2001). O foco principal eram crianças e adolescentes das classes pobres em situações de violação, as quais requerem estratégias de combate.

A história de combate ao trabalho infantil, no Brasil, data de 1891 com a promulgação do Decreto $\mathrm{n}^{0} 1.313$, a primeira norma legal de proteção contra $\mathrm{o}$ trabalho precoce no país, que proibia o trabalho para menores de 12 anos e atividades realizadas no período noturno (Rizzini, 2008). As Cartas Constitucionais de 1934, 1937 e 1946 eram marcos legais que procuravam manter em seus dispositivos a limitação da idade para o ingresso de crianças e adolescentes no mercado de trabalho (Castro, \& Castro, 2002).

Com a Constituição de 1988, implementou-se a Lei Complementar $\mathrm{n}^{\circ}$ 8.069/1990, mais conhecida como Estatuto da Criança e Adolescente (ECA). Trata-se de dispositivo criado com o objetivo de se efetivar a garantia de direitos de crianças e adolescentes. Contém em seus artigos a proibição do trabalho infantil, a proteção ao trabalhador adolescente e define a forma de atuação das entidades governamentais e não governamentais na prevenção e nos casos de violação desse direito.

OEstatutoé um grande avanço na legislação brasileira, porém não é suficiente para proteger crianças e adolescentes da inserção precoce no trabalho. Aliás, a própria terminologia usada pelo Brasil é passível de diversos significados. Ora identifica-se o uso dos termos proibido, prevenção e proteção (Artigos 61 e 70 do ECA) para referir-se ao trabalho infantil; ora usa outros termos como: erradicação do trabalho infantil (usado ao celebrar o compromisso da Presidência da República em 1996, com um conjunto de entidades ao criar o PETI) e que seguia na esteira do termo 
eliminação usado pela Organização Internacional do Trabalho (OIT); luta contra o trabalho infantil, terminologia adotada a partir de 1998 quando a marcha Global deixou clara a amplitude e a complexidade do problema no mundo todo. O termo combate, embora não seja a primeira vez que aparece, torna-se mais constante a partir de 2000, quando o Brasil ratifica a Convenção $\mathrm{n}^{\circ} 182$, que trata da eliminação das piores formas de trabalho infantil, aliada às avaliações das ações empreendidas (dificuldade de ações no trabalho infantil doméstico e informal) até então. De modo que se pode perceber o uso das várias terminologias sinalizando para, por um lado, a dificuldade no trato dessa questão social e, por outro, para o sentido das ações.

$\mathrm{O}$ tamanho da dificuldade e as características do problema encontram-se expressos nos dados que, entre 1992 e 2002, apresentaram uma queda mais drástica dos números. Desde então, tem-se percebido um processo mais lento, experimentando-se, às vezes, até certo crescimento. Segundo Schwartzman (2001), os números do trabalho infantil em 1992 eram de 9,6 milhões de crianças e adolescentes (incluindo as crianças entre cinco e nove anos de idade), mantendo-se com 9,5 milhões ainda em 1995. Isso significa que $22,3 \%$ das crianças brasileiras entre cinco e 17 anos eram trabalhadoras. Em 2003, os números caem para 5,1 milhões; em 2004, 5,3 milhões; em 2005, 5,9 milhões; em 2006, 5,3 milhões; em 2007, 4,8 milhões e, em 2009, 4,4 milhões. Mas os dados oscilam, ora diminuem, ora aumentam. O Censo de 2010 revelou a existência de 3,4 milhões entre dez e 17 anos, mas a Pesquisa Nacional por Amostra de Domicílios - PNAD 2011, que usa outra metodologia, revelou 8,6 milhões entre cinco e 17 anos (PETECA, 2012).

Além da Constituição Federal de 1988, do Estatuto e das disposições da Lei Orgânica da Assistência Social (LOAS) sobre as políticas sociais para garantia de direitos, fez-se necessária a criação de ferramentas de efetivação destes. O PETI constitui uma dessas ferramentas, e sua criação se faz mediante a pretensão da erradicação, iniciando-se, em 1996, nas Carvoarias de Mato Grosso Sul e, posteriormente, estendendo-se para a Bahia - região do sisal e para Pernambuco - região da cana-de-açúcar (Carvalho, 2000). Na Paraíba, a partir de 1999, o PETI chega aos setores da agricultura - cana-de-açúcar e sisal. Em seguida, chega ao Junco do Seridó, onde trabalhadores precoces estavam inseridos nas pedreiras. Em 2000, chega a João Pessoa para retirar as crianças e adolescentes da catação de lixo (Soares, Teixeira, \&Wanderlei, 2003).

Em 2005, o governo federal, com a justificativa de ampliar a cobertura de atendimento, de racionalizar e de aprimorar os processos de gestão e garantir o amparo e a proteção às famílias e adolescentes em situação de risco, integrou o PETI ao Programa Bolsa Família - PBF (Rua, 2007). São beneficiários do Programa crianças e adolescentes egressos do trabalho, na faixa de sete a 15 anos e 11 meses, cujas famílias tenham renda per capita abaixo de $\mathrm{R} \$ 140,00$, que são incluídas no PETI/Bolsa Família via Cadastro Único (Brasil, 2010a).

Ao contrário do que se pretendia, como aponta Rua (2007), em análise acerca das contribuições do PETI após integração com PBF, as metas do Programa não chegam a ser atingidas: nem as de atendimento a crianças e adolescentes do PETI, nem as que eram assistidas pelo PBF e foram encaminhadas ao serviço de convivência e fortalecimento de vínculo. Principalmente, perdeu-se de vista o foco do programa, que era o combate ao trabalho infantil.

No relatório da Associação Nacional dos Centros de Defesa da Criança e do Adolescente - ANCED (2009), levando-se em conta as contribuições do PETI após integração com PBF, constata-se que, ao se destinar grande parte do orçamento às bolsas, deixou-se de investir nas atividades socioeducativas e de convivência. A pesquisa realizada por Cacciamali, Tatei e Batista (2010) corrobora os dados levantados pela ANCED (2009), de que a integração do PETI ao PBF acabou focando apenas o objetivo do Programa Bolsa Família - o de combate à pobreza - deixando de lado o objetivo principal do PETI: a erradicação do trabalho infantil.

Outros autores e instituições (Pinheiro, 2008; Rua, 2007; UNICEF, 2004), em análise das contribuições das políticas públicas através de programas sociais, também têm sinalizado para a pouca eficácia do PETI. Na Análise Situacional realizada pelo o Fundo das Nações Unidas (2004), o financiamento foi apontado como uma das maiores dificuldades de operacionalização do Projeto, assim como a falta de uma ação estratégica adequada para o desenvolvimento de ações geradoras de renda, que promova a inclusão social das famílias dos egressos do trabalho precoce. Sendo assim, é possível afirmar que, após a junção do PETI com o PBF, este assumiu um viés mais compensatório do que emancipatório, não possibilitando a 
autonomia das famílias, o que acarreta uma situação de dependência permanente, podendo afetar suas próximas gerações (Sartori, \& Garcia, 2012).

O Brasil modificou o modelo original do PETI, que aliava ao recurso monetário, destinado a famílias na forma de bolsa, as ações educativas realizadas através da "jornada ampliada" no contraturno da escola. Assim, o país desistiu do primeiro modelo do PETI, e investiu nos "programas focalizados na indigência e aumento do poder de compra" (Behring, \& Boschetti, 2011, p. 185), características presentes no modelo que aglutinou o PETI e o PBF. Retirou-se o foco do trabalho infantil, porque se fez uma leitura de suas causas essencialmente atreladas aos fatores econômicos, leia-se pobreza. Adotou-se a tônica das políticas sociais como incremento no salário indireto pelo Estado, com o investimento em programas de garantia de renda (Behring, \& Boschetti, 2011, p 174). O foco é a situação de risco e, não mais, o processo educativo, como configurava a primeira versão do manual do PETI.

Mas, nas portarias subsequentes do Ministério de Desenvolvimento Social (MDS), em especial a da Tipificação Nacional dos Serviços Socioassistenciais (Brasil, 2009), o foco continua sendo a família, através, porém, de serviços socioassistenciais pautados em práticas protetivas incentivadoras de convivência solidária. Essa tônica é mantida na Resolução $\mathrm{n}^{\circ} 008$ de abril de 2013, do Conselho Nacional de Assistência Social (Brasil, 2013), que dispõe sobre as ações estratégicas do PETI no âmbito do Sistema Único de Assistência Social (SUAS). Nessa perspectiva, o Brasil abandonou o modelo de política que unia educação e complemento de renda ou benefício e educação (Sartori, \& Garcia, 2012).

Há que se acrescentar o significado de socioassistencial, concepção essa discutida por Freire (2005) e retomada por Lima e Carlotto (2009), de acordo com a qual, ao definir educação, o primeiro autor diferencia a educação bancária da educação libertadora. A bancária é vista por ele, entre outras coisas, como assistencialista. Freire (2005) compreende que o assistencialismo rouba ao homem a autonomia, torna-o passivo, domesticado. Lima e Carloto (2009) chamam a atenção de que o termo socioeducativo muda de sentido conforme o contexto e, embora "socioeducativo seja apresentado como uma ação educativa, não é explicitado de que maneira isso deva ocorrer" (p. 136). Não "se verifica clareza de concepção teórica nos documentos do Ministério de Desenvolvimento Social" (p. 128) acerca do que são ações socioeducativas. Logo cabe ao socioeducativo uma pluralidade de ações que não traduzem exatamente uma ação transformadora que possibilite a autonomia e o protagonismo desses cidadãos em processo de desenvolvimento.

Sposito (2009) analisa a produção da pós-graduação em educação, ciências sociais e serviço social, identificando estudos que analisam programas públicos de transferência de renda ou ações governamentais e não governamentais voltadas para adolescentes e jovens pobres. Os estudos identificam que vários desses programas ou atividades se definem como uma proposta socioeducativa. Borges (2002), Fernandes (2005), Leão (2004), Marques (2003) e Perez (2000) revelam que não fica claro o princípio educativo que norteia as atividades desenvolvidas nos programas ou ações, e várias delas "se transformam em políticas de ocupação do tempo e de combate à ociosidade" (p. 149), "em detrimento de uma formação reflexiva capaz de problematizar sua condição social" (p. 151).

Paradoxalmente, enquanto no Brasil o PETI muda, em nível internacional, mostra-se como um dos programas singulares que contribuem nesse empenho contra o trabalho infantil (PETECA, 2012). Diante desse paradoxo, indaga-se: quais as contribuições do Programa de Erradicação do Trabalho Infantil na perspectiva dos educandos e seus familiares? Porque procuram o programa? Tal inserção mudou a vida dos mesmos?

Vale salientar que a Política de Assistência Social é algo relativamente novo no Brasil, sendo criado o Plano Nacional de Assistência Social (PNAS) apenas em 2004, com objetivo de garantir o atendimento às necessidades básicas dos segmentos populacionais vulnerabilizados pela pobreza e exclusão social (Brasil, 2004), priorizando a família como foco de atenção. E é nesse cenário de mudanças que a atuação de psicólogos é demandada. Como recomenda o próprio Conselho Federal de Psicologia, a nova realidade demanda da Psicologia uma atuação junto à coletividade, no sentido de se garantir o direito à assistência social e à vida. Trata-se de um desafio devido à tradição histórica da profissão, exigindo que a atuação da Psicologia não se limite a uma ação estritamente técnica, devendo ser dotada de um aspecto crítico, reflexivo, e, acima de tudo, político (Conselho 
Federal de Psicologia, 2009). O presente estudo se dá também nesse sentido, com a finalidade de contribuir no âmbito das políticas públicas, mas também como forma de legitimar e demarcar o lugar da Psicologia na ação e pesquisa nessa área. Além de contribuir na compreensão dos contextos de desenvolvimento das crianças e adolescentes filhos da classe trabalhadora (Santos, 2011).

\section{Método}

\section{Amostra}

Para a realização da pesquisa, primeiramente foi realizada a identificação dos Núcleos do PETI da cidade João Pessoa, o que nos permitiu contabilizar 27 Núcleos espalhados pelos bairros da cidade, sendo a administração dividida pelo setor público e privado. Em seguida, realizou-se um levantamento documental e de dados acerca do PETI em João Pessoa, a fim de se ter acesso aos números de educandos (crianças e adolescentes entre sete e 15 anos de idade, do sexo feminino e do sexo masculino) e famílias.

A meta da cidade era de 3.112 educandos no ano de 2009. No entanto, de acordo com os documentos cedidos pelo PETI no período da pesquisa, que aconteceu entre os anos de 2009 e 2010, são atendidos 2.265 educandos, sendo 1.574 famílias beneficiadas dos quais, $10 \%$ participaram da pesquisa, mediante sorteio aleatório, contemplando uma amostra de 359 educandos e 153 famílias. No caso do representante da família a ser entrevistado, adotou-se como critério aquele cujo cartão do benefício contivesse seu nome.

\section{Procedimentos}

Após autorização da Secretaria de Desenvolvimento Social (SEDES) da Prefeitura Municipal de João Pessoa, responsável pelo PETI, conforme previsto na Resolução $n^{\circ}$ 196/96 do Conselho Nacional de Saúde, que versa sobre a Ética na pesquisa com seres humanos, o Projeto foi submetido ao Comitê de Ética.

Para a realização da pesquisa, entrou-se em contato com a Coordenação do PETI, para que se tivesse acesso à lista dos participantes do PETI, denominados como Dependentes Ativos, que são os responsáveis pelos educandos e pelo Cartão do Programa Bolsa Família. A partir dos documentos analisados, a equipe de pesquisa fez o contato com os Núcleos do PETI local que atende os educandos e as famílias. Antes das entrevistas, foi explicada a questão do sigilo, do objetivo da pesquisa, e que eles poderiam desistir a qualquer momento se não desejassem mais continuar. Após todos os esclarecimentos, fazia-se o convite para participação na pesquisa, mediante a assinatura do Termo de Consentimento. No caso dos educandos, a assinatura era feita pelos pais ou responsáveis. A entrevista foi individual.

\section{Coleta de dados e tratamento}

Para a obtenção dos dados, foi realizada uma entrevista semiestruturada, realizada, nos dois casos, de forma individual nos próprios núcleos do PETI. As questões versavam sobre o perfil biossociodemográfico dos atores, o significado do PETI para eles, os motivos de inserção dos educandos, os aspectos positivos e negativos acerca do programa, e o que mudou em suas vidas após a entrada no programa. $\mathrm{O}$ instrumento dos educandos continha 42 questões, abertas e fechadas, sendo as abertas relativas ao significado do PETI e aos aspectos positivos e negativos do Programa. Já no instrumento utilizado com os familiares, as questões abertas referiam-se aos aspectos positivos e negativos.

Para análise dos dados, utilizou-se a ferramenta da Análise de Conteúdo Temática de Bardin (2007), optando-se pela técnica de validação por dois juízes, ambos previamente treinados para tal. Em seguida, tanto as questões fechadas como as categorias emergentes da análise de conteúdo compuseram um banco de dados. Para tal, usou-se o software SPSS, versão 18, para contagem de frequências e de percentuais.

\section{Resultados}

A maioria dos educandos encontrava-se entre 10 e 13 anos, com predominância do sexo feminino, de grupo étnico de negros, morenos e mulatos, seguidos de brancos e indígenas em um menor número. Estar cursando o Ensino Fundamental II foi também predominante, com 53,6\% tendo sido reprovados pelo menos uma vez. Dos familiares entrevistados, a maioria encontrava-se na faixa etária entre 31 e 40 anos; eram do sexo feminino; se consideravam como negros, morenos e mulatos; e encontravam-se trabalhando. Em relação à escolaridade, a maioria estudou até o ensino fundamental incompleto. As frequências percentuais desses dados podem ser observadas na Tabela 1.

Quando se indagou aos familiares se eles estavam trabalhando, $58,8 \%$ disseram que não, 
Tabela 1

Dados biosociodemográficos dos participantes.

\begin{tabular}{|c|c|c|c|c|c|c|}
\hline Dados & Educand & & & Famílias & & \\
\hline \multirow{5}{*}{ Idade } & Faixa etária & $\mathrm{N}$ & $\%$ & Faixa etária & $\mathrm{N}$ & $\%$ \\
\hline & 7 a 9 anos & 41 & 11.4 & 19 a 30 anos & 33 & 21.6 \\
\hline & \multirow{2}{*}{10 a 13 anos } & \multirow{2}{*}{203} & \multirow{2}{*}{56.5} & 31 a 40 anos & 87 & 56.9 \\
\hline & & & & 41 a 50 anos & 23 & 15 \\
\hline & 14 a 16 anos & 115 & 32 & 51 a 67 anos & 10 & 6.5 \\
\hline \multirow{3}{*}{ Sexo } & Sexo & $\mathrm{N}$ & $\%$ & Sexo & $\mathrm{N}$ & $\%$ \\
\hline & Feminino & 192 & 53.5 & Feminino & 145 & 94.8 \\
\hline & Masculino & 167 & 46.5 & Masculino & 8 & 5.2 \\
\hline \multirow{4}{*}{ Etnia } & Etnia & $\mathrm{N}$ & $\%$ & Etnia & $\mathrm{N}$ & $\%$ \\
\hline & Branco & 86 & 24 & Branco & 28 & 18.4 \\
\hline & Amarela/Indígena & 20 & 5.6 & Amarela/Indígena & 5 & 3.3 \\
\hline & Negros e Pardos & 253 & 70.5 & Negros e Pardos & 119 & 78.3 \\
\hline \multirow{6}{*}{ Escolaridade } & Série & $\mathrm{N}$ & $\%$ & Série & $\mathrm{N}$ & $\%$ \\
\hline & Educação Infantil & 1 & 0.3 & Fundamental completo & 10 & 7.1 \\
\hline & Fundamental I & 131 & 36.5 & Fundamental Incompleto & 92 & 65.2 \\
\hline & Fundamental II & 202 & 56.3 & Ensino Médio Completo & 16 & 11.2 \\
\hline & Ensino Médio & 24 & 6.7 & \multirow{2}{*}{ Ensino Médio Incompleto } & \multirow{2}{*}{23} & \multirow{2}{*}{16.3} \\
\hline & Acelera & 1 & 0.3 & & & \\
\hline
\end{tabular}

Fonte: Pesquisa Direta, 2009-2010.

e $41,2 \%$ disseram que sim. Dos que disseram sim, as principais atividades apontadas foram: trabalho doméstico, 57,8\%; comerciante e reciclador (a), 6,3\%; ajudantes em serviços gerais, 4,7\%; costureira, $3,1 \%$; outras atividades, $1,6 \%$.

No que versa sobre o significado do PETI, tanto para os educandos quanto para os familiares, emergiram as seguintes categorias: repetição da sigla, funções socioeducativas, retirada da situação de risco. Quando questionados a respeito do motivo de inserção no programa, as categorias que emergiram das respostas dos educandos e dos familiares foram: sair de situações de risco, porque trabalhavam, para fazer reforço escolar, para receber a bolsa. As frequências e porcentagens desses dados podem ser obsevadas na Tabela 2 .

A respeito dos aspectos positivos do PETI, pode-se observar uma congruência nas vozes dos educandos e familiares ao se remeterem às atividades socioeducativas, às brincadeiras e aos educadores. Emergem, porém, outras categorias temáticas que não coin- cidem. Além das categorias citadas acima, destaca-se que os familiares apontam para a retirada da situação de risco (7,9\%), enquanto os educandos apontam para os cursos profissionalizantes $(3,4 \%)$.

Quando os educandos e seus familiares foram questionados a respeito dos aspectos negativos do Programa, as categorias encontradas foram: deveria haver mais atividades, questões infraestruturais, falta de educadores capacitados. Mais uma vez, surgem outras categorias que não são semelhantes nas respostas, dentre as quais se ressalta: que os educandos apontam os cursos profissionalizantes como algo que deveria haver $(0,6 \%)$, e os familiares pedem por mais disciplina no comportamento dos educandos $(3,5 \%)$. As frequências dos aspectos positivos e negativos apontados pelos educandos e familiares podem ser observadas na Tabela 3.

Ao serem indagados a respeito das mudanças proporcionadas a partir da inserção no PETI, mais uma vez encontramos uma homogeneidade nas respostas das duas amostras. Trata-se das categorias: 
Tabela 2

Significados atribuído ao PETI e motivos de inserção no Programa.

\begin{tabular}{|c|c|c|c|c|}
\hline \multirow{2}{*}{ Categorias } & \multicolumn{2}{|c|}{ Educandos } & \multicolumn{2}{|c|}{ Famílias } \\
\hline & $\mathrm{N}$ & $\%$ & $\mathrm{~N}$ & $\%$ \\
\hline \multirow{14}{*}{ Significado do PETI } & \multicolumn{4}{|c|}{ Repetição da sigla } \\
\hline & 96 & 26 & 9 & 6.5 \\
\hline & \multicolumn{4}{|c|}{ Funções socioeducativas } \\
\hline & 74 & 20 & 51 & 37 \\
\hline & \multicolumn{4}{|c|}{ Retirada da situação de risco } \\
\hline & 35 & 9 & 78 & 56.5 \\
\hline & \multicolumn{4}{|c|}{ Projeto para criança e adolescente } \\
\hline & 22 & 6 & - & - \\
\hline & \multicolumn{4}{|c|}{ Outros } \\
\hline & 4 & 1 & - & - \\
\hline & \multicolumn{4}{|c|}{ Não sabe } \\
\hline & 106 & 29 & - & - \\
\hline & \multicolumn{4}{|c|}{ Não respondeu } \\
\hline & 22 & 6 & - & - \\
\hline \multicolumn{5}{|c|}{ Sair da situação de risco } \\
\hline \multirow{19}{*}{ Motivo de inserção } & 80 & 22.4 & 62 & 40.5 \\
\hline & \multicolumn{4}{|c|}{ Porque trabalhavam } \\
\hline & 60 & 16.8 & 30 & 19 \\
\hline & \multicolumn{4}{|c|}{ Para fazer reforço escolar } \\
\hline & 40 & 11.2 & 48 & 31.4 \\
\hline & \multicolumn{4}{|c|}{ Para receber a bolsa } \\
\hline & 31 & 8.7 & 50 & 32.7 \\
\hline & \multicolumn{4}{|c|}{ Criança/adolescente estava em casa sem fazer nada } \\
\hline & 81 & 22.7 & - & - \\
\hline & \multicolumn{4}{|c|}{ Porque quis } \\
\hline & 57 & 16 & - & - \\
\hline & \multicolumn{4}{|c|}{ Porque o educando não tinha com quem ficar } \\
\hline & - & - & 26 & 17 \\
\hline & \multicolumn{4}{|c|}{ Para comer } \\
\hline & - & - & 11 & 7.2 \\
\hline & \multicolumn{4}{|c|}{ O Conselho Tutelar mandou } \\
\hline & - & - & 6 & 3.9 \\
\hline & \multicolumn{4}{|c|}{ Responsável obriga a ir para o PETI } \\
\hline & 8 & 2.2 & - & - \\
\hline
\end{tabular}

Fonte: Pesquisa Direta, 2009-2010.

* O hífen significa que não houve respostas do participante.

retirou da rua $(44,7 \%$ dos educandos e para $34,4 \%$ dos familiares), deixou de trabalhar (18,3\% dos educandos e $18,5 \%$ das famílias) e nada mudou (21,9\% dos educandos e 9,3\% para as famílias). Nas vozes dos familiares, ainda surgiram as categorias: passaram a ter bolsalauxílio (30,5\%), melhora na escolaridade $(0,7 \%)$ e melhora no comportamento $(5,3 \%)$.

\section{Discussão}

Os dados sociodemográficos mostram o predomínio do feminino tanto entre os educandos como entre as famílias de etnia afrodescendente, com baixa escolaridade. No caso dos educandos, $57,7 \%$ já foram reprovados, dos quais $46,3 \%$ já foram reprovados mais de uma vez. 
Tabela 3

Aspectos positivos e negativos do PETI.

\begin{tabular}{|c|c|c|c|c|}
\hline \multirow{2}{*}{ Categorias } & \multicolumn{2}{|c|}{ Educandos } & \multicolumn{2}{|c|}{ Famílias } \\
\hline & $\mathrm{N}$ & $\%$ & $\mathrm{~N}$ & $\%$ \\
\hline & \multicolumn{4}{|c|}{ Atividades socioeducativas } \\
\hline & 178 & 51.9 & 37 & 24.3 \\
\hline & \multicolumn{4}{|c|}{ Brincadeiras } \\
\hline & 81 & 23.6 & 57 & 37.5 \\
\hline & \multicolumn{4}{|c|}{ Os educadores } \\
\hline & 35 & 10.2 & 11 & 7.2 \\
\hline & \multicolumn{4}{|c|}{ Infraestrutura } \\
\hline & 23 & 6.7 & - & - \\
\hline & \multicolumn{4}{|c|}{ Outros } \\
\hline & 24 & 7 & - & - \\
\hline \multirow{18}{*}{$\begin{array}{l}\text { Aspectos } \\
\text { Positivos }\end{array}$} & \multicolumn{4}{|c|}{ Cursos profissionalizantes } \\
\hline & 3 & 3.4 & - & - \\
\hline & \multicolumn{4}{|c|}{ Tudo } \\
\hline & - & - & 16 & 10.5 \\
\hline & \multicolumn{4}{|c|}{ Relações } \\
\hline & - & - & 13 & 8.6 \\
\hline & \multicolumn{4}{|c|}{ Alimentação } \\
\hline & - & - & 5 & 3.3 \\
\hline & \multicolumn{4}{|c|}{ Benefício } \\
\hline & - & - & 1 & 0.3 \\
\hline & \multicolumn{4}{|c|}{ Retirada da situação de risco } \\
\hline & - & - & 12 & 7.9 \\
\hline & \multicolumn{4}{|c|}{ Deveria ter mais atividades } \\
\hline & 146 & 42.7 & 8 & 5.6 \\
\hline & \multicolumn{4}{|c|}{ Falta infraestrutura } \\
\hline & 128 & 37.4 & 18 & 12.5 \\
\hline & \multicolumn{4}{|c|}{ Falta de educadores capacitados } \\
\hline & 25 & 7.3 & 5 & 3.5 \\
\hline Aspectos & \multicolumn{4}{|c|}{ Nada } \\
\hline \multirow[t]{7}{*}{ Negativos } & 22 & 6.4 & 86 & 59.7 \\
\hline & \multicolumn{4}{|c|}{ Outros } \\
\hline & 19 & 5.6 & 15 & 10.4 \\
\hline & \multicolumn{4}{|c|}{ Falta de cursos profissionalizantes } \\
\hline & 2 & 0.6 & - & - \\
\hline & \multicolumn{4}{|c|}{ Falta de disciplina } \\
\hline & - & - & 8 & 5.6 \\
\hline
\end{tabular}

Fonte: Pesquisa Direta, 2009-2010.

* O hífen significa que não apareceu nas respostas da amostra.

Em relação às famílias, a maioria dos responsáveis entrevistados não trabalha. Quando o faz, é no setor serviço, em atividades pouco reconhecidas socialmente, a exemplo de reciclagem, ou em atividades domésticas. Embora as atividades domésticas se configurem como setor de serviços, apresentaram-se, neste artigo, separadamente por dois motivos: primeiro, a maioria das pessoas das famílias entrevistadas são mulheres (que têm o cartão em seu nome), mães que são responsáveis pela família e cujos trabalhos realizados se caracterizam como tal, revelando que a maioria das famílias é mantida por mulheres trabalhadoras domésticas. Segundo, porque as pesquisas mostram que há uma tendência de as crianças e adolescentes do sexo feminino, trabalhadoras precoces, desenvolverem as mesmas atividades das mães (Alberto, Nunes, Cavalcante, \& Santos, 2005; ANCED, 2009; Mendes, 2004).

Como predominam na pesquisa meninas e mães, com baixa escolaridade, para as pesquisadoras isso gera a hipótese de reprodução intergeracional, uma vez que se identificou nessa pesquisa a mudança do modelo de política que investia em educação e renda mínima, para investimento só em renda mínima. A reprodução intergeracional foi identificada em Santos (2011), que identifica que os pais de crianças do PETI também foram trabalhadores precoces e que as meninas tendem a reproduzir a atividade das mães. Assim, quão mais baixo o nível escolar dos pais, maior a tendência de os filhos trabalharem precocemente (Kassouf, 2002).

Apesar de o PETI ser um programa cujo objetivo principal é retirar a criança do trabalho, essa não foi a principal causa de inserção no Programa apontada pelos educandos nem pelos familiares. $O$ que se pode destacar é que metade das crianças e adolescentes das famílias entrevistadas não adentrou o programa diretamente pelo fato de estarem em situação de risco propiciada pelo trabalho infantil e, sim, por outras situações de riscos, entre as quais a situação de rua.

Para educandos e famílias, o PETI é um lugar para onde vão crianças e adolescentes nas seguintes condições: que são retiradas das ruas, para sair da situação de risco, para sair do trabalho. Lá elas contam com as contribuições dos (as) educadores (as) e fazem brincadeiras, atividades esportivas e artísticas e de reforço. Aquilo que o Ministério de Desenvolvimento Social nomina de atividades socioeducativas ou socioassistenciais. Essas denominações não definem qual o projeto educativo adotado nem o que ele visa. Como assinalam Lima e Carloto (2009) e Freire (2005), não se caracteriza por uma concepção de educação que prime pela autonomia e protagonismo; parece mais caracterizar o que Pinheiro (2008) assinala como espaço de depósito ou de contenção de jovens pobres. A falta dessa definição e de um projeto educativo adequado reflete-se nas próprias questões da escola- 
ridade, já que, como apontamos, 57,7\% dos entrevistados já foram reprovados, dos quais $46,3 \%$ já foram reprovados mais de uma vez.

Embora a retirada do trabalho infantil seja vista como um dos objetivos ou contribuições do PETI, o Programa não foi visualizado como o aspecto primordial nem pela totalidade dos educandos e das famílias, não em termos de erradicação, já que apenas $18 \%$ dos dois grupos ressaltaram como contribuição do PETI retirar do trabalho infantil. Então os dados reforçam as concepções de que a mudança do programa o descaracterizou.

Esses dados corroboram pesquisas realizadas por Pinheiro (2008) e Rua (2007), nas quais se verifica que vem ocorrendo uma crescente descaracterização da função do programa, que não é mais a de erradicação do trabalho infantil. Além disso, a integração do PETI ao PBF focou apenas neste último programa e no combate à pobreza, deixando de lado o investimento nas atividades e no foco no combate ao trabalho infantil (ANCED, 2009; Cacciamali, Tatei, \& Batista, 2010).

Uma das funções do PETI é atuar como ação educativa complementar à escola, na qual devem ser realizadas atividades de apoio ao processo de aprendizagem, por meio de reforço escolar, aulas de informática, línguas estrangeiras, direitos humanos, entre outros. Esse aspecto pode ser evidenciado a partir da categoria melhora na escolaridade (Brasil, 2004).

Apesar de ambos os grupos de participantes citarem como positivas as atividades socioeducativas - que ocorrem no contraturno escolar -, ainda aparecem respostas dos educandos no sentido de realização de cursos profissionalizantes. A questão da formação profissional surge justamente no discurso dos educandos mais velhos, que já se encontram quase para sair do programa, por conta da idade, e que, por sua vez, já sentem a necessidade da formação profissional, levando-se em conta o que o contexto vem exigindo desses jovens. Segundo a Cartilha do PETI (Brasil, 2004), cursos profissionalizantes não devem ser oferecidos para os educandos e, sim, para os familiares, visando à geração de renda destes. Afinal, o trabalho infantil é proibido pela Constituição Brasileira; só é permitido o trabalho enquanto aprendiz, entre 14 e 16 anos, como determina o Art. 60 do ECA.

Os aspectos negativos apontados pelos participantes (deveria haver mais atividades, questões infraestruturais, falta de educadores capacitados) são de suma importância para um bom funcionamento do programa. De acordo com as "Orientações Técnicas - Gestão do Programa de Erradicação do Trabalho Infantil no SUAS” (Brasil, 2010a), os serviços do PETI devem ser oferecidos em locais apropriados, sem apresentar risco à segurança e à saúde das crianças e dos adolescentes, devendo possuir boa iluminação, ventilação, condições higiênicas, sanitárias e de segurança ideais. Já as atividades devem proporcionar uma expansão do universo informacional, artístico e cultural dos educandos, além de instigar o desenvolvimento de potencialidades, habilidades, talentos e trabalhar questões de formação cidadã (Brasil, 2010b).

Então, diante do que o PETI determina nas orientações e o que de fato essa pesquisa encontrou, vê-se que, na perspectiva das famílias e dos educandos, as contribuições, através das atividades realizadas em espaços sem infraestrutura adequada e nos quais faltam educadores capacitados, são negativas. Mas se, por um lado, a falta de capacitação dos educadores é apresentada pelos educandos e famílias como um aspecto negativo, paradoxalmente os educadores também são apresentados pelos dois grupos como um dos aspectos positivos do PETI. Ou seja, mesmo sem capacitação, parece que esses profissionais estão tentando fazer seu trabalho. Tais aspectos apontados pelos educandos e pelas famílias revelam o investimento inadequado por parte do município, já que à gestão municipal compete a disponibilização de recursos e capacitação dos educadores. Os dados do Fundo das Nações Unidas (2004) e da ANCED (2009) já sinalizavam o financiamento como uma das maiores dificuldades de operacionalização do Projeto e da falta de investimento nas atividades.

No que se refere à falta de educadores capacitados, nota-se um desacordo com o que está explicito na Cartilha do PETI, na qual se afirma que os profissionais que atuam nesse serviço devem possuir certas habilidades, como a questão de estar atento à demanda de novas atividades e de saber respeitar diferenças culturais, de faixa etária, realidade local, entre outras (Brasil, 2004).

De acordo com Carvalho (2000), o PETI surge como uma ferramenta cuja finalidade é erradicar o trabalho infantil, na tentativa de garantir o amparo e a proteção às famílias de crianças e adolescentes em situação de risco. Esses aspectos foram explicitados tanto pelos educandos quanto por seus familiares ao serem indagados sobre as mudanças que 
ocorreram depois da inserção no PETI. Constata-se assim que, apesar de repetirem a sigla do Programa, ao serem indagados sobre o que significa, essa repetição revela na verdade uma reprodução automática, como uma forma de sinalizar que ele tem um significado. Mas este não traduz a experiência que se tem com ele, já que para eles é apresentado como uma retaguarda para a retirada de situações de risco de outra ordem, como a saída da rua, o combate à pobreza oportunizada pela bolsa (o benefício) como um auxílio. Logo apresentam como mudanças justamente o que se almeja com o programa ou aquilo que se tornou, a partir da integração com o Programa Bolsa Família, combate à pobreza e retirada das crianças e adolescentes em situação de risco. Esses dados corroboram o que Behring e Boschetti (2011) e Cacciamali et al. (2010) identificavam: o Brasil mudou o modelo do PETI e passou a investir nos programas focalizados no combate à pobreza e aumento do poder de compra. Os dados revelam assim que, a seu modo, as famílias e os educandos captavam essas mudanças, ressignificando-as.

No entanto, faz-se mister esclarecer que, apesar de essas mudanças terem sido apontadas pelos familiares e educandos, diversos estudos, dentre os quais se pode destacar o de Rua (2007), apontam que as metas do programa não chegam a ser atingidas e, principalmente, que se perdeu de vista o foco do programa, que era o combate ao trabalho infantil. A questão do distanciamento do enfoque do programa pode ser evidenciada pelas próprias respostas de alguns familiares que ressaltaram como mudança a bolsa. Esse benefício deveria ser repassado às famílias, inicialmente, enquanto não recebiam os cursos profissionalizantes, mas sempre almejando a inserção destes no mercado de trabalho. Nota-se, porém, que a bolsa passou a exercer papel de destaque no programa, e os outros aspectos como as atividades educativas foram perdendo espaço, dando lugar às atividades assistenciais (Brasil, 2010b).

A expressão do desejo de mais disciplina no comportamento dos educandos demonstra que os familiares concebem o programa como tendo o papel de controlar, de impor limites, de moldar comportamentos. Assim, a necessidade de mais atividades, articulada com a falta de infraestrutura, a falta de capacitação dos professores e a demanda por mais disciplina parecem tirar do PETI o caráter de espaço educativo. Ou seja, voltado para uma complementação do papel da escola ou do que poderia ser uma educação integral, o substitui pelo modelo socioassistencial, tônica que se apresenta a partir de 2009, quando o modelo deixa de ser de erradicação do trabalho infantil e voltase para o fortalecimento de vínculo (Brasil, 2010b).

Esta pesquisa identifica, a partir dos dados oriundos dos participantes, vários paradoxos. O PETI retira das ruas, da situação de risco, concede um benefício financeiro para as famílias, oferece atividades socioassistenciais (brincadeiras, merenda, reforço, artes e lazer) para crianças e adolescentes, através de educadores sem capacitação. Os participantes avaliam que o programa contribui, mas precisa melhorar, precisa de mais atividades, de mais educadores; precisa de infraestrutura e de mais disciplinamento. Os participantes avaliam que o PETI contribui, mas tem menos a ver com erradicação do trabalho infantil e mais a ver com atendimento assistencial. Essa perspectiva foi sendo adotada pelo Programa e incidiu para o que Sposito (2009) identifica como programas voltados para jovens pobres, uma ação que se denomina socioeducativa, mas sem deixar claro o princípio educativo que norteia as atividades desenvolvidas, que mais se caracterizam por políticas de ocupação do tempo e de combate à ociosidade.

Esta pesquisa apresentou pluralidades que revelam o significado e a contribuição do Programa para educandos e famílias que o descaracterizam enquanto política de erradicação ou de combate ao trabalho infantil. Tornou-se, então, uma política pública de retaguarda para a situação de risco vivenciada por crianças e adolescentes que compõem um determinado segmento social. Pelo identificado nos dados oriundos das entrevistas dos participantes, tem, apesar dos aspectos negativos, a sua contribuição: mudou a vida dos educandos, retirou das ruas, retirou da situação de risco e mudou a vida das famílias que passaram a receber uma bolsa, um benefício financeiro.

As políticas públicas são ferramentas importantes para o enfrentamento ao trabalho infantil, como uma forma de se efetivar direitos, principalmente diante das questões sociais que emergem da relação capital trabalho. Ou seja, em sociedades desiguais as políticas públicas funcionam como promoção de cidadania (Behring, \& Boschetti, 2011). Diante da pluralidade acessada através desta pesquisa, chama-se atenção para a importância da Psicologia olhar para as histórias de vida desses sujeitos de forma crítica e reflexiva. Faz-se mister levar em conta o lugar que o PETI ocupa 
na vida desses sujeitos, apesar das falhas apontadas pelos participantes, entendendo a realidade concreta na qual essas crianças, adolescentes e familiares estão inseridos e a contribuição desse contexto para o desenvolvimento biopsicossocial. A prática da Psicologia nas políticas públicas deve levar em conta tais questões, as diferenças concretas que existem nas condições de vida dos brasileiros, no caso em questão de sujeitos em processo de desenvolvimento egressos do trabalho infantil e inseridos em ações de proteção e promoção dos direitos.

\section{Considerações finais}

A pesquisa realizada permite refletir sobre as mudanças pelas quais o PETI vem passando e como vem contribuindo na vida dos beneficiários, a partir das perspectivas tanto dos educandos como dos familiares. Para ambas as amostras, o PETI se configura prioritariamente como um espaço para onde vão crianças e adolescentes retiradas das ruas, para sair da situação de risco. Ou seja, para além do objetivo da erradicação do trabalho infantil, o Programa tem combatido mais a pobreza e retirada das crianças e adolescentes em situação de risco, principalmente após a integração com o PBF, o que acaba por descaracterizar o PETI como uma política pública de erradicação do trabalho infantil.

\section{Referências}

Alberto, M. F. P., Nunes, T. S., Cavalcante, C. P. S., \& Santos, D. P. (2005). O trabalho infantil doméstico em João Pessoa - PB: um diagnóstico rápido à luz das piores formas de trabalho infantil. João Pessoa, PB: OIT.

Associação Nacional dos Centros de Defesa da Criança e do Adolescente-ANCED. (2009). Análise sobre os direitos da criança e do adolescente no Brasil: relatório preliminar da ANCED. São Paulo: Autor.

Bardin, L. (2007). Análise de conteúdo. (70a ed.). Lisboa: Edições 70.

Behring, E. R., \& Boschetti, I. (2011). Política social: fundamentos e história. (9a ed.). São Paulo, SP: Cortez.

Borges, Z. M. (2002). Um olhar sobre o atendimento sobre crianças e adolescentes: o princípio educativo das atividades realizadas pelas organizações não governamentais da cidade de Goiânia (Dissertação de Mestrado). Universidade Federal de Goiás, Goiânia, GO.

Brasil. Ministério da Saúde. Conselho Nacional de Assistência Social. (2013). Resolução $N^{o} 08$, de 18 de abri
Apesar disso, os participantes destacam a contribuição do PETI como um espaço em que os educandos fazem brincadeiras, atividades esportivas, artísticas, de lazer, além do reforço escolar. Pelo número significativo de reprovações, pode-se concluir que as atividades não vêm sendo planejadas de modo a contribuir nessa direção, indicando a falta de um projeto pedagógico adequado, já que as atividades oferecidas são mais assistenciais do que educativas e transformadoras.

Outro fator relacionado às atividades oferecidas diz respeito à falta de capacitação dos educadores, apontada tanto pelos educandos como pelas famílias como um aspecto negativo, o que revela um investimento insuficiente por parte do município para a capacitação contínua, estabelecida pelas diretrizes, fazendo com que esse trabalho seja executado muitas vezes a partir do senso comum.

Os resultados a que se chegou, na pesquisa que origina este artigo, levam as autoras a sugerir que as políticas públicas de combate ao trabalho infantil devem apoiar-se, então, em um projeto pedagógico que garanta uma escolarização adequada, com atividades realizadas por profissionais preparados e capacitados, em uma infraestrutura adequada. As relações da implicação do trabalho infantil e da condição econômica refletem-se na baixa escolarização em um nível intergeracional, denotando uma repetição desse ciclo.

de 2013. Dispõe sobre as ações estratégicas do Programa de Erradicação do Trabalho Infantil - PETI. Brasília, DF: o autor.

Brasil. Ministério de Desenvolvimento Social e Combate à Fome (2004). Programa de erradicação do trabalho infantil - Cartilha do PETI. Brasília, DF: o autor.

Brasil. Ministério do Desenvolvimento Social e Combate à Fome (2009). Tipificação Nacional de Serviços Socioassistenciais: documento base: fichas de serviços. Brasília: o autor.

Brasil. Ministério de Desenvolvimento Social e Combate à Fome (2010a). Orientações técnicas: Gestão do Programa de Erradicação do Trabalho Infantil no SUAS. Brasília, DF: o autor

Brasil. Ministério de Desenvolvimento Social e Combate à Fome (2010b). Orientações técnicas sobre o serviço de convivência e fortalecimento de vínculos para crianças e adolescentes de 6 a 15 anos. Brasília: o autor. 
Alberto, Maria de Fatima Pereira; Pessoa, Manuella Castelo Branco; da Costa, Rafa ela Rocha; Belém, Kassia Kiss Grangeiro; e Silva, Suzany Ludimila Gadelha (2016) Concepções sobre o PETI.

Cacciamali, M. C., Tatei, F, \& Batista, N. F. (2010). Impactos do programa Bolsa Família federal sobre o trabalho infantil e a frequência escolar. Revista de Economia Contemporânea, 14(2), 269-301. doi:10.1590/S1415-98482010000200003

Campos, H. R., \& Alverga, A. R. (2001). Trabalho infantil e ideologia: contribuição ao estudo da crença indiscriminada na dignidade do trabalho. Estudos de Psicologia (Natal), 6(2), 227-233. doi:10.1590/S1413-294X2001000200010

Carvalho, M. C. B. (2000). O combate ao trabalho infantil na voz e na agenda da sociedade e do estado brasileiro. In C. C. Arregui (Org.), Erradicação do trabalho infantil (pp.13-41). São Paulo, SP: EDUC.

Castro, J. A. L., \& Castro, D. S. L. (2002). Aspectos jurídicos da proibição do trabalho infantil e da proteção ao trabalho adolescente. In M. E. Marques, \& M. Almeida. Trabalho infantil: a infância roubada (pp. 61-77). Belo Horizonte: PUC Minas.

Conselho Federal de Psicologia. (2009). A prática profissional dos(as) psicólogos(as) nos serviços de enfrentamento à violência, abuso e exploração sexual de crianças e adolescentes. Brasília, DF: o autor

Fernandes, R. S. (2005). As marcas do vivido sentido: memórias de jovens ex-frequentadores de um projeto de educação não formal (Tese de Doutorado). Universidade Estadual de Campinas, Campinas, SP.

Freire, P. (2005). Pedagogia do oprimido. (44a ed.). São Paulo, SP: Paz e Terra.

Fundo das Nações Unidas para a Infância - UNICEF. (2004). Análise situacional do programa de erradicação do trabalho infantil. Brasília, DF: o autor.

Kassouf, A. L. (2002). Aspectos socioeconômicos do trabalho infantil no Brasil. Brasília, DF: Secretaria de Estado dos Direitos Humanos.

Leão, G. M. P. (2004). Pedagogia da cidadania tutelada: lapidar corpos e mentes: uma análise de um programa federal de inclusão social para jovens pobres (Tese de Doutorado). Faculdade de Educação da Universidade de São Paulo, São Paulo, SP.

Lima, E. S., \& Carloto, C. M. (2009). Ações socioeducativas: reflexões a partir de Freire. Emancipação, 9(1), 127-139. doi:10.5212/Emancipacao.v.9i1.127139

Marques, C. G. (2003). A semiformação institucionalizada em um projeto de semiprofissionalização (Dissertação de Mestrado). Universidade Metodista de Piracicaba, Piracicaba, SP.

Mendes, R. (2004). O Brasil sem trabalho infantil doméstico. In M. F. P. Alberto, Trabalho infanto-juvenil e direitos humanos (pp. 37-42). João Pessoa, PB: Editora Universitária.

Nascimento, A. M. (1995). Curso de Direito do Trabalho. (1 la ed.). São Paulo: Saraiva.

Perez, M. A. R. (2000). Análise das iniciativas de atendimento para crianças e adolescentes em situação de risco social no município de Santo André (1991-1998) (Dissertação de Mestrado). Universidade de São Paulo, São Paulo, SP.

Pinheiro, D. A. A. A.(2008). Jornada Ampliada do PETI em Manaus: a perspectiva dos educandos e monitores (Dissertação de Mestrado). Universidade Federal da Paraíba, João Pessoa, PB.

Programa de Educação contra a Exploração do Trabalho da Criança e do Adolescente - PETECA. (2012). Ranking do trabalho infantil nos estados brasileiros: 5 a 17 anos: PNAD 2011. In Programa de Educação contra a Exploração do Trabalho da Criança e do Adolescente - PETECA [BLOG]. Recuperado de http:// peteca2008.blogspot.com.br/2012/09/ranking-dotrabalho-infantil-no-brasil_23.html?spref=bl

Rizzini, I. (2008). O século perdido: raízes históricas das políticas públicas para a infância no Brasil. São Paulo, SP: Cortez.

Rua, M. G. (2007). Avaliação da integração do Programa de Erradicação do Trabalho Infantil (PETI) ao Programa Bolsa Família (PBF). Brasília, DF: Fórum Nacional de Prevenção e Erradicação do Trabalho Infantil.

Santos, D. P. (2011). As implicações do trabalho precoce em adultos (Dissertação de Mestrado). Universidade Federal da Paraíba, João Pessoa, PB.

Sartori, E., \& Garcia, C. H. M. (2012). Políticas compensatórias versus emancipatórias: desafios para implementação de programas de geração de renda às famílias em situação de risco. Revista de Administração Pública, 46(2), 425-452. doi:10.1590/S0034-76122012000200005

Schwartzman, S. (2001). Trabalho infantil no Brasil. Brasília, DF: Organização Internacional do Trabalho.

Soares, A. M., Teixeira, D. M., \&Wanderlei, M. A. P. (2003). Trabalho infantil nas pedreiras: uma experiência avaliativa do PETI no município do Junco do Seridó - PB. In M. F. P. Alberto (Org.), Crianças e adolescentes que trabalham: cenas de uma realidade negada (pp. 267275). João Pessoa, PB: Universitária/UFPB.

Sposito, M. P. (Coord.) (2009). Estado da arte sobre juventude na pós-graduação brasileira: educação, ciências sociais e serviço social (1999-2006). Belo Horizonte, MG: Argvmentvm. 


\section{Maria de Fatima Pereira Alberto}

Docente da Universidade Federal da Paraíba, João

Pessoa - PB. Brasil.

E-mail: jfalberto@uol.com.br

Manuella Castelo Branco Pessoa

Doutoranda pela Universidade Federal da Paraíba, João Pessoa - PB. Brasil.

E-mail: manucastelobranco2@gmail.com

\section{Rafaela Rocha da Costa}

Mestre pela Universidade Federal da Paraíba, João

Pessoa - PB. Brasil.

E-mail: rafaelarer@gmail.com

\section{Kassia Kiss Grangeiro Belém}

Mestre pela Universidade Federal da Paraíba, João

Pessoa - PB. Brasil.

E-mail: kassiakiss19@yahoo.com.br

\section{Suzany Ludimila Gadelha e Silva}

Mestre pela Universidade Federal do Rio Grande do Norte, Natal - RN. Brasil.

E-mail: suzany_ludimila@hotmail.com
Endereço para envio de correspondência:

Rua Marieta Steimback Silva, n 320, Apto 2802A, Bairro Miramar, CEP 58.043-320. João Pessoa - PB. Brasil.

Recebido: 02/09/2013

Reformulado: 04/07/2015

Aprovado:31/03/2016

Received: 09/02/2013

Reformulated: 07/04/2015

Approved:03/31/2016

Recibido: 02/09/2013

Reformulado: 04/07/2015

Aceptado:31/03/2016

Como citar: Alberto, M. F. P., Pessoa, M. C. B., Costa, R. R., Belém, K. K. G., \& Silva, S. L. G. (2016). Programa de erradicação do trabalho infantil: concepções de educandos e famílias. Psicologia: Ciência e Profissão, 36(2): 458-470. doi:10.1590/1982-3703001842013

How to cite: Alberto, M. F. P., Pessoa, M. C. B., Costa, R. R., Belém, K. K. G., \& Silva, S. L. G. (2016). PETI (Child Labor Eradication Program): students' and families' conceptions. Psicologia: Ciência e Profissão, 36(2): 458-470. doi:10.1590/1982-3703001842013

Cómo citar: Alberto, M. F. P., Pessoa, M. C. B., Costa, R. R., Belém, K. K. G., \& Silva, S. L. G. (2016). PETI (Programa de Erradicación del Trabajo Infantil): concepciones de estudiantes y familias. Psicologia: Ciência e Profissão, 36(2): 458-470. doi:10.1590/1982-3703001842013 